\title{
Uso de aprendizagem baseada em projetos com apoio de outras metodologias ativas para promover aprendizagem ativa no ensino de biotecnologia
}

Francine Valenga francine.valenga@pucpr.br 0000-0001-8837-8785 Pontifícia Universidade Católica do Paraná, Curitiba, Paraná, Brasil

Angela Raimondi angela.raimondi@grupomarista.org 0000-0002-0986-8987

Pontifícia Universidade Católica do Paraná, Curitiba, Paraná, Brasil

Kamila Colombo kamila.colombo@pucpr.br 0000-0003-0287-6412

Pontifícia Universidade Católica do Paraná, Curitiba, Paraná, Brasil

Keliani Bordin keliani.bordin@pucpr.br 0000-0003-1605-5690

Pontifícia Universidade Católica do Paraná, Curitiba, Paraná, Brasil

\section{RESUMO}

A aprendizagem tradicional, focada em quadro e giz, tende a diminuir seu espaço entre educadores e educandos. Com isso o uso de diferentes metodologias ativas pode ser uma excelente alternativa aos estudantes passivos, despertando maior autonomia e significado na aprendizagem. Em vista disso, um modelo inovador de ensino foi proposto na disciplina de Biotecnologia, que está na grade de Engenharia Química. Para a preparação das aulas teóricas foram usadas estratégias, como Blended Learning, Peer Instruction, Team Based Learning (TBL) e Técnica de Aplicação para Resposta Imediata (TARI), reduzindo consideravelmente os momentos expositivos. A base da disciplina foi o Project Based Learning $(\mathrm{PjBL})$, mediante o qual era proposto aos acadêmicos desenvolver um produto de origem biotecnológica, no decorrer das aulas práticas. Os métodos de ensino adotados consideraram: o tema de estudo; o tempo de realização; as formas de avaliar o aprendizado; e a dinâmica para trabalhar com os discentes em sala. Por meio delas, percebeu-se que os estudantes adquiriram o conhecimento básico necessário para desenvolver os projetos, de modo a contemplar os resultados de aprendizagem esperados ao final da disciplina. Conclui-se também que, a aprendizagem quando aliada a um significado faz com que os discentes tornem-se mais motivados e participativos no processo. Além disso, o uso de PjBL, apoiado por outras metodologias, despertou nas equipes maior autonomia e dedicação, deixando-os mais engajados, críticos e envolvidos.
\end{abstract}

PALAVRAS-CHAVE: Metodologias ativas. PjBL. Aprendizagem ativa. 


\section{INTRODUÇÃO}

Um bom ensino é aquele em que os estudantes conseguem chegar ao final da disciplina aptos a desempenhar os resultados de aprendizagem definidos. Para esse sucesso, o professor deve estar comprometido com o processo de ensinoaprendizagem e ter responsabilidade sobre as atividades propostas. Planejar e estudar são práticas comuns na carreira docente. Além disso, é preciso conhecer os estudantes, por meio da promoção de atividades prévias para verificar como e com qual profundidade trabalhará os temas de estudo. Durante o período de aulas, deve propor iniciativas que incentivem a reflexão, pois é a partir de um problema que os discentes verificam a importância e o significado de aprender.

A passividade dos estudantes, que muitas vezes são tratados como meros ouvintes das informações disponibilizadas pelo professor, é uma das maiores críticas ao ensino tradicional. Frequentemente, tais conteúdos não se relacionam aos conhecimentos prévios que os acadêmicos construíram ao longo de sua vida e, dessa forma, a aprendizagem não é significativa (MOREIRA, 2005; GUIMARÃES, 2009). Segundo Pelizzari et al. (2002), para haver aprendizagem significativa são necessárias duas condições. Primeiramente, o estudante precisa ter disposição para aprender - se o indivíduo quiser memorizar o conteúdo de forma arbitrária e literal, esta aprendizagem será mecânica. A segunda condição relaciona-se ao aprendizado pela experiência, o conteúdo deve ser potencialmente significativo, ou seja, tem que ter: significado lógico, que depende somente da natureza do conteúdo; e significado psicológico, uma experiência que cada indivíduo tem. Assim, cada um filtra as informações que têm significado para si.

Até recentemente, o ensino tradicional caracterizava-se, em sua maior parte, por utilizar livros, cadernos, quadro e giz. No entanto, a maior disponibilidade de ferramentas educacionais, como as novas tecnologias disponíveis, vem modificando esse conceito. Os estudantes, acostumados com diversos devices, tendem a se sentir desmotivados a esse modelo. Por isso, métodos com a utilização de smartphones e outros dispositivos proporcionam uma nova maneira de tornar a aprendizagem mais interessante, buscando aproximar o discente para torná-lo presente e autônomo no processo de ensino-aprendizagem.

Uma das formas de romper a passividade é colocar o discente frente a problemas reais, demandando seu conhecimento para resolver e explorar novas tecnologias digitais. Diversas abordagens pedagógicas podem ser utilizadas nesse contexto, por meio das metodologias ativas de ensino. As aprendizagens nesse modelo usam desafios e atividades; são planejadas, acompanhadas e avaliadas com apoio de tecnologias, estimulando o estudante a pesquisar, avaliar situações com uma visão crítica sobre o conteúdo, fazer escolhas, assumir alguns riscos, aprender pela descoberta e a caminhar do simples para o complexo (MORÁN, 2015).

Além disso, as metodologias ativas são processos que visam a estimular a autoaprendizagem e a curiosidade do acadêmico para pesquisar, refletir e analisar possíveis situações para a tomada de decisão, sendo o professor o facilitador desse processo (BERBEL, 2011; DIESEL; BALDEZ; MARTINS, 2017).

O Project Based Learning (PjBL) é uma dessas estratégias que possibilitam com que estudantes engajem-se e adquiram conhecimentos e habilidades, por meio de experiências contextualizadas, aplicando a teoria na resolução de problemas a 
partir de situações reais (PEREIRA; BARRETO; PAZETI, 2017). Seu uso também possibilita um ensino pluralista e permite abordagens de discussões coletivas, críticas e reflexivas, o que resulta em momentos ricos de aprendizagens significativas (BEHRENS; JOSÉ, 2001).

Os projetos desenvolvidos em PjBL são baseados em perguntas ou problemas desafiadores, que fazem com que os discentes desenhem métodos e hipóteses de resolução de problemas, trabalhem de forma autônoma e ao final tenham como resultado: um produto ou uma apresentação (THOMAS, 2000; BOUBOUKA; PAPANIKOLAU, 2013); principal diferencial da estratégia comparada as demais.

No ensino na área de engenharia, alguns trabalhos foram realizados para oportunizar essa aprendizagem. Carvalho et al. (2014) usou o PjBL para promover habilidades transversais entre os estudantes e elaborar trabalhos multidisciplinares, o que impactou na habilidade de comunicação, visão crítica e capacidade de gerenciamento.

Sabendo da grande importância e de como essas estratégias influenciam na aprendizagem dos discentes, o presente estudo teve como objetivo propor uma disciplina totalmente voltada ao uso de metodologias ativas no processo de ensino-aprendizagem. Dessa maneira, foi proposto o uso do PjBL nas aulas práticas, tendo a sua fundamentação trabalhada em aulas teóricas, por meio de diferentes abordagens de metodologias ativas.

\section{MATERIAL E MÉTODOS}

O modelo inovador de ensino foi proposto na disciplina de Biotecnologia, no curso de Engenharia Química, vinculado à Escola Politécnica, no câmpus Curitiba da Pontifícia Universidade Católica do Paraná (PUCPR). Obrigatória no $6^{\circ}$ período, a disciplina trabalha com acadêmicos que tem maior nível de maturidade e percepção da busca às respostas sobre determinados problemas, assim como, já possuem conhecimentos básicos que podem ser explorados pelo docente. $\mathrm{Na}$ turma de aplicação do estudo, haviam 35 estudantes matriculados e as aulas eram divididas a cada semana entre: duas aulas práticas em laboratório; e duas aulas teóricas, cada uma com duração de 45 minutos.

No planejamento da disciplina, os resultados de aprendizagem desejados aos discentes incluíam:

- Desenvolver, trabalhando em equipes, produtos de origem biotecnológica, determinando os processos fermentativos em escala laboratorial e piloto, caracterizando os produtos obtidos.

- Caracterizar microrganismos e suas aplicações em indústrias de Biotecnologia.

- Selecionar as matérias-primas para processos fermentativos.

- Avaliar como os parâmetros de processo podem influenciar nos produtos desejados.

Assim, as atividades foram elaboradas com base nos resultados de ensino estabelecidos previamente. Os métodos escolhidos consideraram: o tema de estudo; o tempo de realização; as formas de avaliar a aprendizagem; e a dinâmica para trabalhar com os estudantes em sala. As aulas foram ministradas em salas 
com mobiliário e organização recomendadas para a aplicação das metodologias ativas, com mesas e carteiras móveis que facilitam a movimentação para a formação de equipes. O conteúdo teórico foi abordado empregando diferentes estratégias, como Blended Learning, Peer Intruction, Team Based Learning (TBL) e Técnica de Aplicação para Resposta Imediata (TARI), o que reduziu consideravelmente o número de aulas expositivas.

Em complementação, nas aulas práticas da disciplina, as primeiras semanas concentraram-se na oferta de ações que pretendiam inspirar os estudantes em métodos e condições a serem explorados em seus futuros projetos. As aulas consistiam no isolamento e caracterização de microrganismos, microscopia, biomoléculas como fonte de matérias-primas e processos fermentativos. Os exercícios introdutórios foram propostos já que, para esse público, foi o primeiro contato com a área biológica. Posteriormente, foi elaborada uma atividade de $\mathrm{PjBL}$, na qual os estudantes propuseram um produto de origem biotecnológica, a ser desenvolvido durante as aulas práticas.

Para tanto, inicialmente, os discentes foram divididos em equipes heterogêneas, formadas por até quatro componentes, permanecendo todo o semestre no mesmo grupo, em aulas teóricas e práticas. O questionário utilizado para a separação dos grupos foi adaptado do formulário desenvolvido pela equipe docente do Centro de Ensino e Aprendizagem (CrEAre) da PUCPR (Figura 1), com o intuito de obter equipes mistas de trabalhos e, com isso, obter melhor repetibilidade dos resultados. 
Figura 1 - Questionário aplicado para dividir estudantes em equipes. Questionário do $1^{\circ}$ dia de aula de aula - Biotecnologia

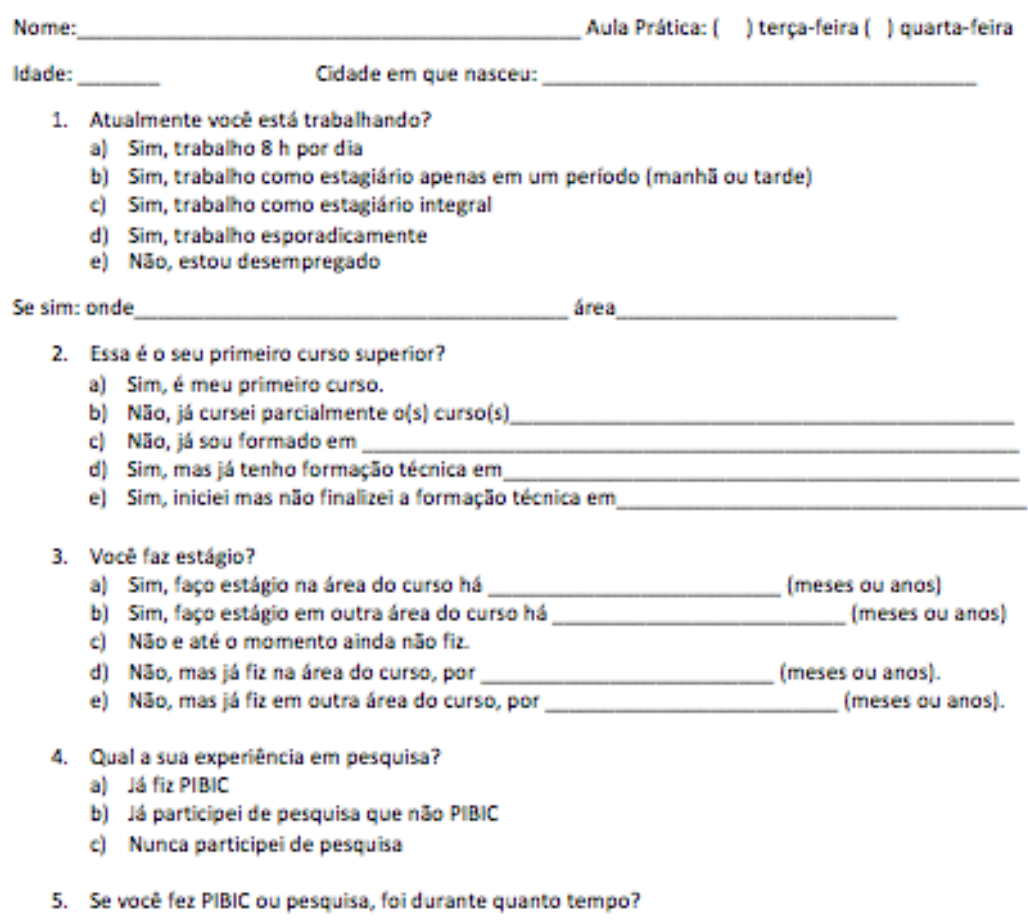

6. Assinale em todas as letras qual das opçães mais se encaixa no seu perfil: a) As pessoas costumam a gostar do que eu escrevo

( ) concordo totalmente ( ) concordo parcialmente ( ) discordo totalmente ( ) discordo parcialmente

b) Eu me sinto à vontade para falar em público

( ) concordo totalmente ( ) concordo parcialmente ( ) discordo totalmente ( ) discordo parcialmente

c) Eu tenho facilidade para trabalhar em grupo

() concordo totalmente () concordo parcialmente ( ) discordo totalmente ( ) discordo parcialmente

d) Quando em grupo costumo a ser o responsável por direcionar as atividades da equipe

( ) concordo totalmente ( ) concordo parcialmente ( ) discordo totalmente ( ) discordo parcialmente

e) Gosto muito da área de biologia

( ) concordo totalmente ( ) concordo parcialmente ( ) discordo totalmente ( ) discordo parcialmente

O Aline von Bahten - CrEAdre - Centro de Ensipa e Aprendizagema PUCPR, Modelo de çuestionário para formaçăo de equipes - dezembro 2016, revisado em fevereiro 2017 (adaptado).

(Fonte: CrEAre)

Após a formação das equipes, os estudantes foram informados sobre as instruções do projeto, o qual foi dividido em três partes: planejamento e escrita; execução; e apresentação do produto final. Para a escrita do projeto, os discentes receberam, na segunda semana de aula, um arquivo de orientações sobre os tópicos que deveriam ser abordados e o que era necessário desenvolver, em equipe, durante a disciplina. 0 prazo de entrega da primeira fase foi limitado para a sétima semana de aula, quando, em acordo com o conteúdo teórico, os acadêmicos disponibilizavam de conhecimentos prévios para a elaboração de um produto de origem biotecnológica. Também foi disponibilizado aos estudantes um arquivo contendo as rubricas de correção, para direcionar o projeto e a apresentação, conforme as exigências do professor.

Além da parte escrita, os acadêmicos entregaram uma planilha contendo todos os materiais e o planejamento do que utilizariam em cada uma das cinco 
aulas práticas, correspondentes a execução. Durante essas semanas, os estudantes abordaram o isolamento e a caracterização do microrganismo trabalhado, a esterilização dos materiais, a inoculação, o processo fermentativo e a caracterização e recuperação do produto final.

As duas últimas semanas de aula, foram dedicadas a apresentação do projeto e do produto final, de forma oral pelas equipes, sendo avaliados por dois professores da instituição, fundamentados nas rubricas de correção previamente disponibilizadas.

\section{RESULTADOS E DISCUSSÕES}

\section{DIVISÃO DA SALA POR EQUIPES}

O questionário (Figura 1) levou em conta o perfil e características dos estudantes, com o objetivo de obter grupos de trabalho heterogêneos. Dessa maneira, o professor fez a divisão das equipes de modo que cada uma tivesse representantes e perfis diferentes uns dos outros.

Como muitos estudantes não tinham contato prévio, foram realizadas atividades iniciais para promover integração entre eles, na primeira aula teórica. $O$ exercício consistia na criação de um nome e um logo, para cada equipe, que seria usado no semestre para identificá-los. Logo, os grupos apresentaram e explicaram suas criações para os colegas com um cronômetro de cinco minutos projetado em tela, para que se organizassem em função do tempo. A ideia de escrever os nomes foi interessante, porque gerou uma excelente interação e, a maioria dos discentes, pareceram se divertir com a atividade. Das oito equipes formadas, apenas uma não quis participar e nem dar nome para identificação do grupo. As denominações variaram, conforme criatividade e produtos a serem desenvolvidos. A Figura 2 mostra exemplos produzidos pelas equipes.

Para dar continuidade a essa primeira etapa, os times tiveram mais dez minutos para escrever as regras que deveriam ser cumpridas pelos membros da equipe durante a execução do projeto. Essas normas foram criadas por eles e cada membro teve de prometer cumpri-las. Além disso, o comprometimento, de cada um, foi avaliado pela equipe, a cada entrega do trabalho (Figura 2). Quanto às regras, também foi perceptível que os acadêmicos gostaram da possibilidade de conceber os próprios critérios de cobrança. $O$ fato de não serem avaliados por normas predeterminadas fez com que se sentissem parte importante do processo avaliativo. No entanto, vale ressaltar que existiram grupos que não souberam estabelecer parâmetros e mantiveram as exigências básicas. 
Figura 2 - Identificação e regras criadas pelas equipes para desenvolvimento das atividades durante todo o semestre.

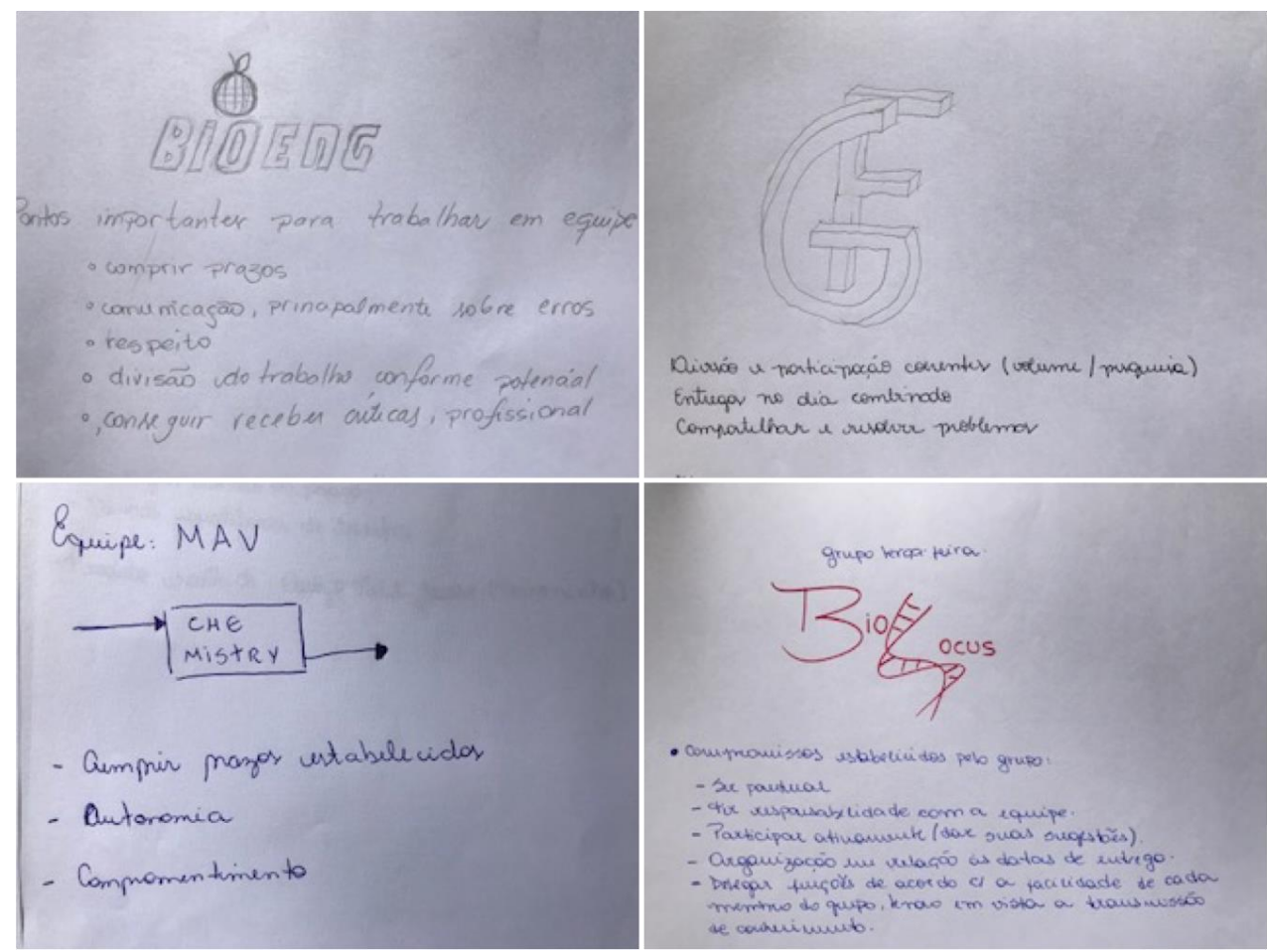

(Fonte: Autora)

Para finalizar esse dia de aula, as equipes tiveram mais 30 minutos para pesquisar um produto viável de elaboração durante as aulas práticas preestabelecidas. Além do produto, foi solicitado aos estudantes que pesquisassem sobre o processo de produção e analisassem a viabilidade de execução no período proposto, levando em consideração as limitações laboratoriais. Com relação às pesquisas, todos fizeram e determinaram os passos iniciais. Uma pesquisa simples foi efetuada, porém, com produtos possíveis de serem concretizados. Algumas equipes ficaram em dúvida e propuseram mais de um produto, a fim de realizar a decisão conforme o decorrer das aulas.

As semanas seguintes tiveram aulas estruturadas, de modo que a teoria e a execução das práticas em laboratório fornecessem conhecimentos estruturantes para embasar a parte escrita do projeto e foram realizadas com a turma dividida em suas equipes (Figura 3), para que as discussões ocorressem de forma a facilitar o desenvolvimento dos projetos.

Figura 3 - Estudantes discutindo, em suas equipes, as atividades desenvolvidas em sala de aula teórica.

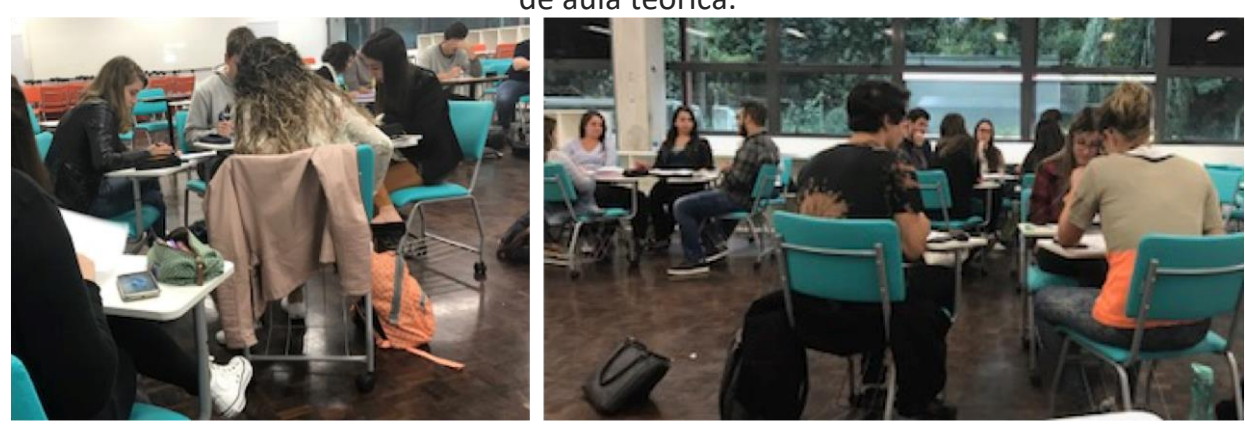

(Fonte: Autora) 


\section{METODOLOGIAS EM AULAS TEÓRICAS}

Nas aulas teóricas foram planejadas diferentes metodologias ativas de ensino. Para o melhor aproveitamento do período em sala e otimização do conhecimento teórico, durante o semestre explorou-se o Blended Learning, modalidade de aprendizagem de Ensino Híbrido. Segundo Staker e Horn (2012) e Valente (2014) esse é um tipo de programa de educação formal que mescla momentos em que o estudante estuda os conteúdos e instruções usando recursos on-line e outros, em que o ensino ocorre em uma sala de aula, podendo interagir com outros alunos e com o professor. Com isso, leituras e vídeos eram recomendados como atividades extraclasse aos estudantes.

Para avaliar essas atividades extraclasse e verificar os conhecimentos prévios, em algumas aulas teóricas foram feitas questões de Peer Intruction, método criado pelo professor Eric Mazur, que baseia-se no estudo anterior de materiais disponibilizados pelo docente e na apresentação de questões conceituais, em sala de aula, para que os acadêmicos discutam entre si. Sua meta principal é promover a aprendizagem dos conceitos fundamentais, relacionados aos temas de estudo, por meio da interação entre estudantes (MAZUR, 2015). Na atividade elaborada em sala, utilizou-se sites específicos de click answers para que os discentes respondessem as questões pelo celular, sendo as respostas projetadas em tempo real e sem identificação. Conforme sua realização, em caso de divergência nas respostas, o professor solicitava aos estudantes que discutissem sobre o tema e reavaliassem suas escolhas. Desse modo, as aulas promoveram debates relevantes, até mesmo levantando hipóteses que o próprio docente não havia ponderado. Segundo a técnica, são nessas interações que a aprendizagem normalmente acontece. Em alguns momentos, houve a necessidade da intervenção do docente, com uma explanação breve do conteúdo, quando identificado que havia dúvida em relação aos conceitos. Salienta-se que na turma avaliada, foi melhor qualificado a aplicação de, no máximo, quatro questões, por assunto. Até esse valor, os estudantes participaram com afinco, mais do que isso, havia um início de dispersão e alguns já não se empenhavam nas discussões.

A dinâmica envolvendo click answers foi importante para avaliar o conhecimento dos estudantes e auxiliar na orientação das aulas. Dependendo das respostas, a aula tomava diferentes rumos. Entretanto, para que isso ocorra, o professor deve estar bem preparado, caso tenha que retomar assuntos ou iniciar discussões que ainda não foram praticadas em aula. A maior dificuldade observada foi fazer com que os acadêmicos percebessem que responder pelo smartphone não era apenas uma atividade divertida, mas sim, um exercício com fins pedagógicos.

O método de TBL, baseado no trabalho de Bollela et al. (2014), foi aplicada em alguns momentos nas aulas teóricas. Uma das ações consistia em entregar uma lista de exercícios de múltipla escolha, para os estudantes resolvessem. Individualmente, deviam assinalar suas respostas e as pontuar. Na etapa seguinte, o grupo reunia-se para discutir e decidir qual a resposta seria considerada correta. Finalmente, as equipes foram unidas, duas a duas, para um novo ciclo de debate e maior uniformidade de respostas. Após os grupos atingirem um consenso, solicitou-se que avaliassem suas respostas utilizando uma cartela de TARI (Figura 4), que é similar a uma raspadinha, sendo raspada a letra que os estudantes acreditam ser a correta. Essa estratégia permitiu um feedback imediato, 
demonstrando os assuntos dominados com maior facilidade e aqueles que requerem maior dedicação e estudo.

Figura 4 - Cartela de TARI com respostas marcadas.

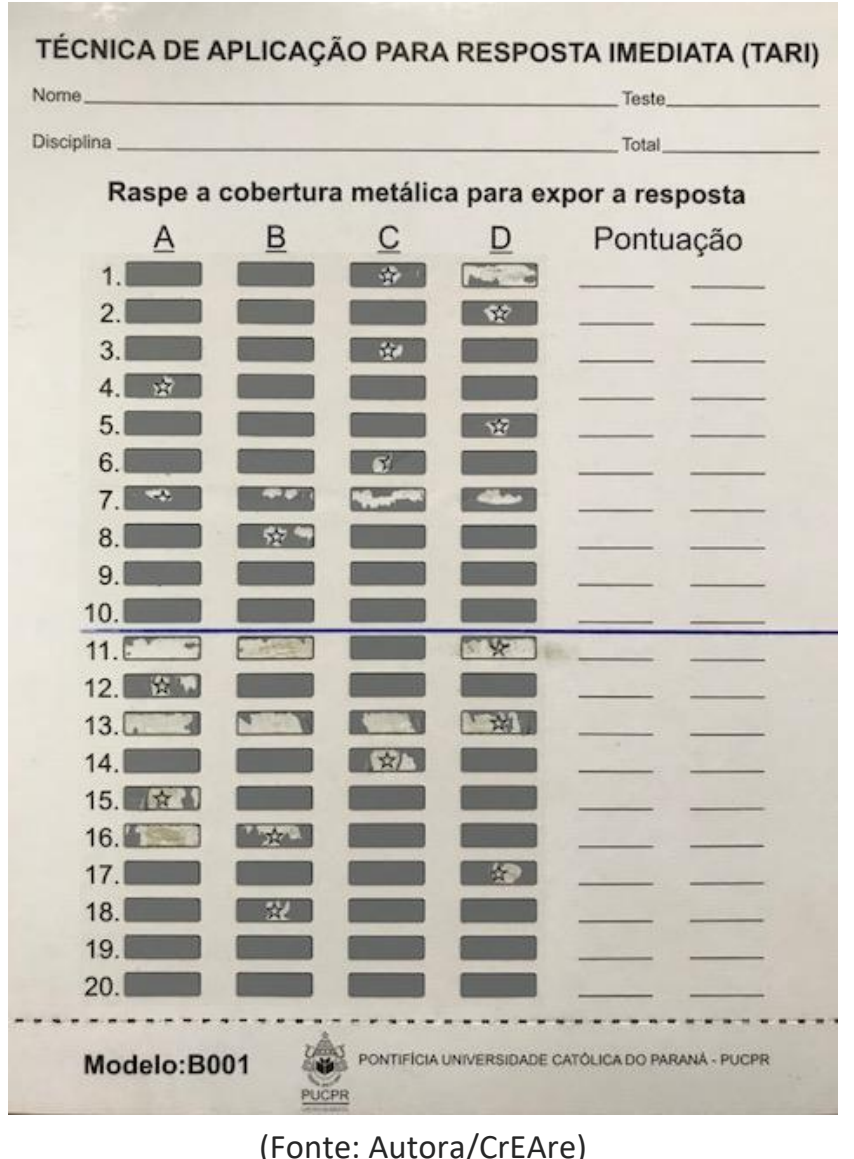

As atividades com uso de TARI foram elogiadas pelos estudantes. Durante a realização, a turma ficou agitada e promoveu diversas discussões, primeiro nos seus respectivos grupos e depois, entre equipes. A cada resposta raspada, os times comemoravam ou lamentavam, o que demonstrava a motivação em realizar a atividade. $\mathrm{O}$ fato de, simplesmente, rasparem uma cartela e distribuírem notas para as questões, já tornou a aula dinâmica e motivadora. Constatou-se que essas foram as aulas com maior debate, porque os discentes afirmaram não querer perder pontos e pelo anseio de descobrir as respostas.

No decorrer do semestre, foram propostos alguns Estudos de Caso, metodologia considerada uma excelente maneira de trazer uma abordagem holística e interativa para o ensino-aprendizagem (FEAGIN; ORUM; SJOBERG, 1991). Seu principal diferencial é adotar uma abordagem orientada para perguntas e não baseada em soluções (GRAHAM, 2010). Com isso, os Estudos de Caso fundamentaram-se em simular situações reais, que podem ter diferentes desfechos, conforme forem conduzidas as respostas. Brevemente, nas aulas, os estudantes recebiam um arquivo contendo o case e, nas equipes, solucionavam as questões propostas. As respostas eram discutidas em sala de aula entre os colegas. $\mathrm{Em}$ algumas aulas, foram sorteadas as equipes que iniciariam os debates e, normalmente, havia 15 minutos de explanação dos conteúdos, distribuídos de acordo com a necessidade. Por vezes, ocorreram intervenções do professor antes 
da leitura do Estudo de Caso, no meio da discussão ou até, durante as discussões dos estudantes para explicar algo. Além das questões formais, propostas no final da atividade, a ferramenta de click answers também foi utilizada para avaliar o conhecimento e aprendizagem dos estudantes.

Dentre as metodologias aplicadas em sala de aula, o Estudo de Caso foi uma das preferidas pelos discentes, pois participaram com mais comprometimento do que nas outras. Ao realizarem as atividades perceberam, na maioria das vezes, a importância e a aplicação dos temas de estudo, além de aumentarem a credibilidade da atividade inovadora junto ao professor. Percebe-se então, que essas foram as aulas em que os estudantes foram conquistados pelo fato de quererem trocar o quadro e o giz, por discussões e aplicações.

No final de cada bimestre, os estudantes avaliaram as aulas e colocaram, de forma anônima, sugestões e críticas para que melhorias pudessem ser efetuadas. Os feedbacks auxiliaram na preparação das aulas, sendo úteis no planejamento. No entanto, observou-se a necessidade de realizar essa pesquisa sem identificação, para obter observações imparciais. De modo geral, os estudantes gostaram das aulas por serem diferentes e pelo estímulo a discussão e ao senso crítico entre eles.

\section{DESENVOLVIMENTO DO PROJETO EM AULAS LABORATORIAIS}

Em paralelo ao período inicial do semestre, no qual os estudantes ainda estavam em pesquisa e redação do projeto, foram executadas atividades básicas de Biotecnologia. Foram propostas atividades para desenvolverem em suas equipes e discutirem com as demais no laboratório, a fim de avaliar qual seria a melhor solução para determinado problema. Normalmente, cada grupo trabalhava com uma condição específica, para que fosse possível gerar discussões e reflexões ao final dos encontros.

A segunda parte das aulas laboratoriais foi dedicada a aplicação dos processos fermentativos para obtenção dos produtos. Cada grupo planejou o agendamento de aulas, além da listagem de materiais e equipamentos necessários, conforme suas pesquisas. Para auxiliar no projeto, foram montadas duas rubricas de avaliação e protocolo de autocorreção: o primeiro, um protocolo direcionado a escrita e planejamento do projeto; a segunda, uma rubrica voltada ao projeto final, incluindo a avaliação das análises de produto. Os estudantes tinham acesso a esses apontamentos, de modo a saber como seriam avaliados pelo trabalho.

As rubricas de avaliação foram um ponto relevante na disciplina, sendo uma referência para as equipes. Com elas, os estudantes tinham a informação de como seriam cobrados e com qual intensidade. Portanto, a partir desse método, não houve mais reclamações com relação as notas nos projetos, já que sabiam o que estava faltando ou ainda, se a atividade teria sido realizada de maneira superficial. As rubricas e o protocolo de autocorreção são ferramentas que, em princípio, são trabalhosas para serem feitas, mas que, uma vez elaboradas, simplificam o trabalho posterior do professor.

Em dois momentos, ao longo da execução do projeto: na semana intermediária e ao final do projeto; todos os membros das equipes avaliaram o grupo entre si, dando sugestões, elogios e críticas, auxiliando na composição das notas finais. Dessa maneira, os grupos conheciam os critérios nos quais poderiam 
ser penalizadas pelos próprios membros. Isso fez com que a maioria dos estudantes trabalhasse efetivamente para não serem prejudicados.

Os produtos selecionados foram de diferentes processos biotecnológicos, como a produção de etanol, ácido láctico, quitosana, celulose etc. (Figura 5).

Figura 5 - Exemplos de materiais produzidos pelas equipes durante as aulas práticas.
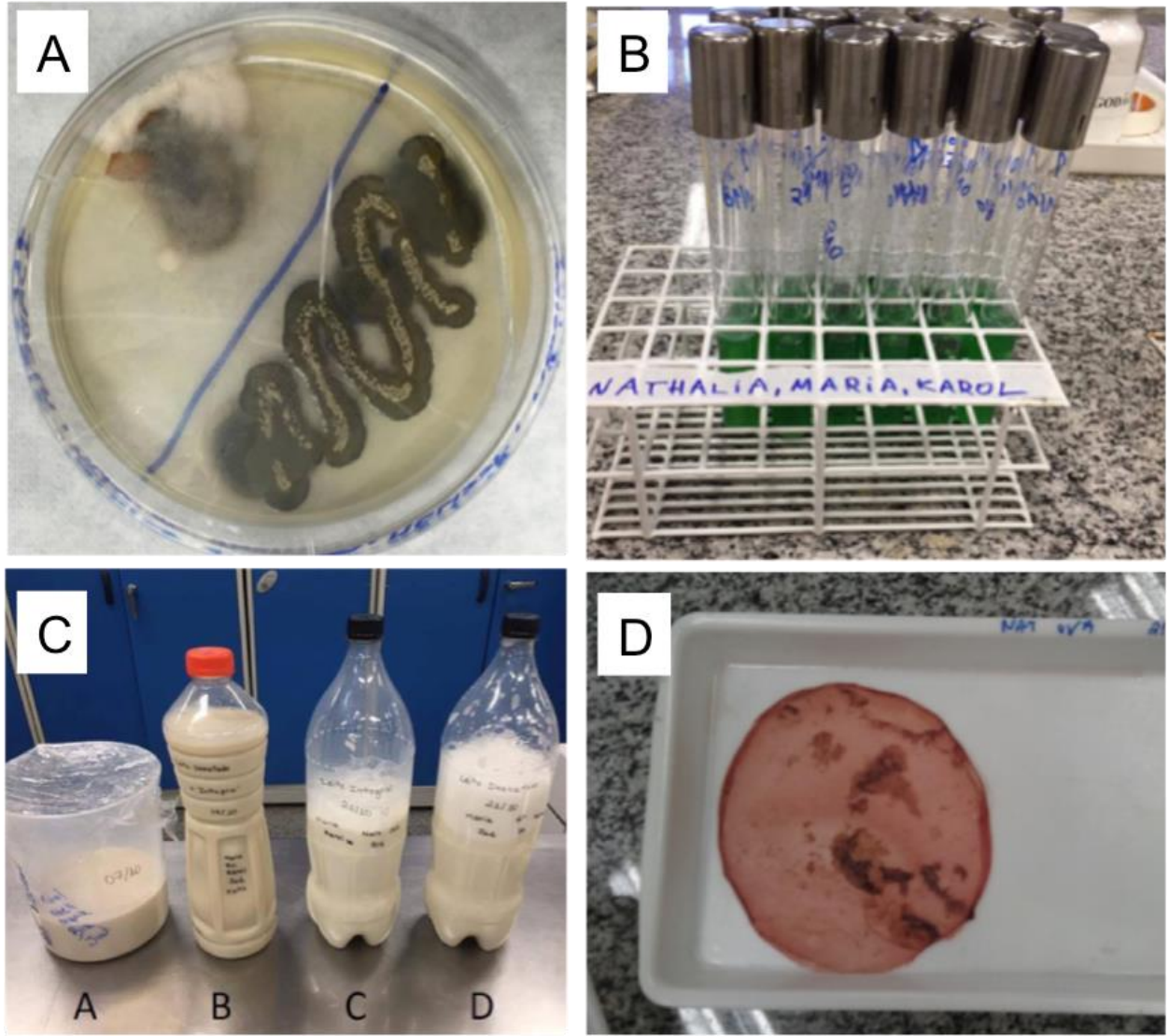

(Fonte: Autora. Legenda da figura: A) Fungo isolado para a produção de quitosana; B) Análises de meios de cultura para produção de ácido láctico; C) Bebidas fermentadas lácteas, com diferentes composições de substrato; D) Celulose bacteriana)

Alguns dos produtos desenvolvidos pelos estudantes foram alimentos, por exemplo, queijo, salame e iogurte de soja. Nesses casos, incluíram-se análises de coliformes e análises sensoriais, de acordo com a legislação vigente no país.

Poucos casos necessitaram de análises mais específicas. Por exemplo, uma equipe produziu um carboidrato, a partir de um fungo extraído de um material contaminado. Para valorizar o trabalho desses estudantes, uma cooperação com os professores da pós-graduação foi efetuada para realizar alguns experimentos não usuais na graduação, como análises de infravermelho, microscopia eletrônica e composição elementar para certificar o produto formado.

Ao finalizar a disciplina, foi proposta uma apresentação do trabalho para todos os colegas da sala, com uma arguição, frente a dois docentes da universidade. Todos membros da equipe deveriam apresentar e responder questões dos professores.

Alguns times empenharam-se com destaque no PjBL. Buscaram informações e esforçaram-se para fazer as atividades, inclusive, desenvolvendo práticas 
extraclasse. Entretanto, houveram aqueles que fizeram o mínimo programado. Portanto, ainda existem algumas tradições de ensino que precisam ser superadas. Há uma cultura de ensino tradicional que deve ser mudada entre os estudantes, mas também junto aos professores.

A autonomia dos acadêmicos é ainda um pouco limitada, porém, usualmente, melhora no decorrer do semestre. Mesmo com maior entusiasmo dos estudantes pelo aprendizado, não foi possível simplesmente passar uma atividade e não a acompanhar, ou seja, houve necessidade de assistência em todas as aulas. No entanto, é importante salientar a importância da independência dos discentes e que, o excesso de intervenções pode prejudicar o processo de aprendizado. Essas atitudes são muito próximas, mas devem ser cautelosas para não perderem a importância das atividades.

\section{CONCLUSÕES}

Os usos de diferentes metodologias de ensino fizeram com que, em geral, as aulas fossem muito bem aproveitadas e resultaram em um produto final melhor do que o esperado. Analisou-se que os estudantes estavam mais motivados e participativos em comparação as aulas regulares, ministradas anteriormente. Além disso, percebeu-se que as atividades desenvolvidas demonstraram ser viáveis, despertando o interesse pela Biotecnologia.

Sabe-se que, às vezes, existem turmas mais resistentes, que podem ter o perfil de não querer discutir ou não querer interagir tanto, talvez até por não considerar as atividades importantes. Dessa forma, para o sucesso na execução da atividade, inicialmente deve-se mostrar a relevância das novas metodologias, explicar o que será feito e o porquê é uma das etapas essenciais para o sucesso das atividades. Nessa disciplina, a partir do momento em que iniciou-se esse processo, a produtividade das aulas melhorou. Os estudantes começaram a se interessar e levar mais a sério o programa ativo da disciplina.

O feedback dos acadêmicos indicou que a maioria gostou das aulas por estimular uma discussão e desenvolver uma visão crítica. No entanto, ainda há alguns poucos estudantes que relataram a preferência pela aula tradicional, indicando que inovar nas metodologias é um desafio para o professor.

A aplicação de metodologias ativas depende também do rendimento de cada turma e, ao longo do semestre, é necessário adaptar conforme o andamento. A aplicação dessas estratégias deve, antes de tudo, ser bem planejada e esse desafio torna os docentes mais fortes e confiantes. As mensagens positivas recebidas, ao final da disciplina, gratificam o trabalho realizado, pois de alguma maneira, modificou o processo de ensino-aprendizagem do estudante.

\section{AGRADECIMENTOS}

Os autores agradecem a Pontifícia Universidade Católica do Paraná (PUCPR) e a Finep - Inovação e Pesquisa, pelo apoio financeiro e pedagógico. 


\title{
The use of project based learning with the support of other active methodologies to promote active learning in Biotechnology classes
}

\begin{abstract}
Traditional learning focused on lecturing tends to narrow its gap between educators and learners. With this, the use of different active methodologies can be an excellent alternative to passive students, creating greater autonomy and meaning in learning. An innovative model of classes was proposed in the discipline of Biotechnology, which is in the grade of Chemical Engineering. For the preparation of the theoretical classes different active methodologies were used for example Blended Learning, Peer Instruction, Team Based Learning (TBL) and Immediate Response Application Technique (TARI), reducing to only a few moments of lectures. The basis of the discipline was the Project Based Learning (PjBL) methodology, in which it was proposed for students to develop a product of biotechnological origin to be executed in practical classes. The chosen methods took into consideration the theme of study, the time of classes, ways to evaluate the learning and the dynamics to work with the students in the laboratory. With these innovative classes, it was realized that the students acquired the basic knowledge necessary to develop the projects in order to contemplate the minimum learning outcomes expected at the end of the course. With this, it is concluded that learning when allied with a meaning makes students more motivated and participatory in the process. The use of PjBL supported by other methodologies provided in the teams greater autonomy and dedication, leaving them also more motivated, critical and involved.
\end{abstract}

KEYWORDS: Active methodology. PjBL. Active learning. 


\section{REFERÊNCIAS}

BERBEL, N. As metodologias ativas e a promoção da autonomia dos estudantes. Semina: Ciências Sociais e Humanas. Londrina: v. 32, n. 1, p. 25-40, 2011.

BERHENS, M. A.; JOSÉ, E. M. A. Aprendizagem por projetos e os contratos didáticos. Revista Diálogo Educacional. Curitiba: v.2, n. 3, p. 77-96, 2001.

BOLLELA, V. R.; SENGER, M. H.; TOURINHO, F.S.V.; AMARAL, E. Aprendizagem baseada em equipes: da teoria à prática. Medicina (Ribeirão Preto), v. 47, n. 3, p. 293-300, 2014.

BOUBOUKA, M.; PAPANIKOLAU, K. A. Alternative assessment methods in technology enhanced Project-based learning. International Journal of Learning Technology, v. 8, n. 3, p. 263-296, 2013.

CARVALHO, D.A.; ALMEIDA, M.T.; NEVES JUNIOR, S.B.; SANTOS E SILVA, S.A.A; CYRILLO, Y.M.; GOMES, F.J. A estratégia do PjBL no século XXI: Utilização das ferramentas digitais. Revista Eletrônica de Engenharia Viva. p. 75-89. 2014.

DIESEL, A.; BALDEZ, A.L.S.; MARTINS, S.N. Os princípios das metodologias ativas de ensino: uma abordagem teórica. Revista Thema. Pelotas: Instituto Federal de Educação, Ciências e Tecnologia Sul-Rio-Grandense, v. 14, n. 1, p. 268-288, 2017.

FEAGIN, J. R.; ORUM, A. M.; SJOBERG, G. A Case for the study case. North Carolina: University of North Carolina Press, 1991.

GRAHAM, A. Como escrever e usar estudos de caso para ensino e aprendizagem no setor público. Brasília: ENAP, 2010.

GUIMARÃES, C. C. Experimentação no ensino de química: caminhos e descaminhos rumo à aprendizagem significativa. Revista Química Nova na Escola (QNEsc). Sociedade Brasileira de Química, v. 31, n. 3, p. 23-35, 2009.

MAZUR, E. M. Peer Instruction: a Revolução da Aprendizagem Ativa. Porto Alegre: Penso, 2015.

MORÁN, J. Mudando a educação com metodologias ativas. In: SOUZA, C. A.; MORALES, O. E. T. (Orgs.). Coleção Mídias Contemporâneas. Convergências Midiáticas, Educação e Cidadania: aproximações jovens. Ponta Grossa: Foca Foto - Pró-Reitoria de Extensão e Assuntos Culturais (PROEX)/Universidade Estadual de Ponta Grossa (UEPG), v. 2, p. 15-33, 2015. Disponível em: $<$ http://www2.eca.usp.br/moran/wp- 
content/uploads/2013/12/mudando_moran.pdf>. Acesso em: 27 de março de 2018.

MOREIRA, M. A. Aprendizagem significativa crítica. Porto Alegre: Instituto de Física da Universidade Federal do Rio Grande do Sul (UFRGS), 2005. Disponível em: <https://www.if.ufrgs.br/ moreira/apsigcritport.pdf>. Acesso em: 10 de março de 2018.

PELIZZARI, A.; KRIEGL, M. L.; BARON, M. P.; FINCK, N. T. L.; DOROCINSKI, S. I. Teoria da aprendizagem significativa segundo Ausubal. Revista PEC. Curitiba: v. 2, n. 1, p. 37-42, 2002.

PEREIRA, M. A. C.; BARRETO, M. A. M.; PAZETI, M. Application of Project-Based Learning in the first year of an Industrial Engineering Program: lessons learned and challenges. Production (ABEPRO), v. 27, p.1-13, 2017.

STAKER, H.; HORN, M. B. Classifying K-12 Blended Learning. Mountain View, CA: Innosight Institute, 2012

THOMAS, J. W. A review of research on Project-based learning. The Autodesk Foundation, 111 Mclnnis Parkway. San Rafael, California, 2000. Disponível em: <http://www.bobpearlman.org/BestPractices/PBL_Research.pdf>. Acesso em: 26 set. 2018.

VALENTE, J. A. Blended-learning e as mudanças no ensino superior: a proposta de sala de aula invertida. Educar em Revista, n. 4, p. 79-97, 2014. 
Recebido: 2018-03-28

Aprovado: 2018-10-16

DOI: $10.3895 /$ rbect.v12n2.8096

Como citar: VALENGA, F.; RAIMONDI, A.; COLOMBO, K.; BORDIN, K. Uso de aprendizagem baseada em projetos com apoio de outras metodologias ativas para promover aprendizagem ativa no ensino de biotecnologia. Revista Brasileira de Ensino de Ciência e Tecnologia, v. 12, n. 2, 2019. Disponível em:

<https://periodicos.utfpr.edu.br/rbect/article/view/8096>. Acesso em: xxx.

Correspondência: Francine Valenga - francine.valenga@pucpr.br

Direito autoral: Este artigo está licenciado sob os termos da Licença Creative Commons-Atribuição 4.0 Internacional. 